\title{
Research on Course Teaching Model Reform Based on "Reversing Classroom" Teaching Mode
}

\author{
Xi Li \\ Changchun Sci-Tech University, Changchun, Jilin, China, 130600
}

Keywords: Flip Classroom, Teaching Model, Reform

\begin{abstract}
The "flip classroom" model of the Internet for the realization of the media is not simply to replace the classroom face to face, but from the structure of the dismantling of the traditional teaching process. Based on the characteristics of our school and the characteristics of the course of digital media art and the current situation of students 'learning and learning, this paper constructs the teaching video development of teachers' teaching curriculum, the self-learning of students before class, the interaction as the core, the construction of curriculum problems, four modules of the "flip classroom" teaching model.
\end{abstract}

\section{An Analysis of Teaching Environment in the Background of Internet and Times}

In the traditional classroom teaching process, in order to achieve the teaching objectives, need to rely on the teacher in the classroom to explain. This brings a lot of problems, such as the lack of high-level teachers and the imbalance of educational resources, even the same professional students in the same grade will be due to this objective factors lead to uneven teaching and quality. With the promulgation of the "Opinions of the State Council on Actively Promoting the Internet + Action" in 2015, it is necessary to explore new ways of providing educational services through the Internet. "Internet +" concept is proposed from the national and government levels to the education sector to bring new opportunities and development model. And "Internet + education" for the development of colleges and universities to bring a new teaching model and teaching ideas. Internet as a new social existence will be deeply integrated in all aspects of education, change the way education activities, improve the quality of education.

\section{Build "Flip Classroom" Teaching Model}

To the Internet for the realization of the media "flip classroom" model is not simply to replace the classroom face to face, but from the structure of the dismantling of the traditional teaching process in the inherent teaching mode, the transmission of knowledge through the teacher in the classroom to explain, While the "flip classroom" model pay more attention to the interaction between students and teachers, the interaction between students. So that the traditional model of passive instillation, into active communication, classroom activities become more vivid, the understanding of knowledge points is more efficient. Reshaping the teaching of the temporal and spatial structure and teaching process of teachers and students off.

Although the classroom has a great advantage in cultivating students' awareness of self-learning and improving their learning efficiency, it is not appropriate to take into account the deep-rooted habits of the three institutions. So what knowledge to choose and when to implement it is particularly important. For the basics and introductory content, we should still take the traditional model of preaching, with the aim of getting started with the help of the teacher, taking the foundation of the students, laying the foundation for the focus and difficulty of each course in the professional course, and expanding the knowledge content. Choose the "flip classroom" new model, so that students can enjoy the new learning model to bring the improvement of learning efficiency, but also to avoid the strange knowledge of learning to bring frustration.

Through the study of the implementation methods and teaching cases of "flip class" in domestic 
and foreign countries, this paper summarizes the effective classroom management experience and mature implementation methods, combined with the characteristics of our school and the professional courses of digital media and the current state of study and learning Based on the construction of appropriate "flip classroom" teaching model. The flip classroom model is divided into teacher teaching curriculum teaching video development, students before class learning, interactive as the core, the problem building, teaching reflection four modules. In the implementation of the process of flip, there are strict implementation of norms and processes.

Course Teaching Video Development. In the "flip classroom" in the traditional teaching mode of the knowledge of the preview and teaching arrangements arranged by the students themselves to complete, so that more teachers need to provide students with adequate learning resources. Course teaching video is mainly based on the needs of each lesson on the teaching content for the students to design and develop series of micro-class, practice question bank, production materials and other learning resources. Establish a learning community (micro group / QQ group) and network learning platform for students to pre-class preview and after-school exchange interaction. With the development of curriculum teaching video, we should first clear the objectives that students must master, and the content of the video that ultimately needs to be expressed. Second, the development of video material and video development should be based on the appropriate learning methods and habits of different students and different class learning differences, in order to improve and truly achieve the ideal teaching method of individualized teaching.

Students Learning before Class. After teaching the classroom, the teaching mode changes the teaching mode of teaching, and the students use the teaching video resources such as the micro course or PPT as the guidance of the text of the "task order" as the "new teaching material" New content, "the introduction of students can be based on their own situation to develop personalized learning model, as well as their own arrangements for learning time. Reconstruct the classroom structure from the dimension of time and space.

Take Interact as the Core to Complete the Knowledge Internalization and Sublimation. In pre-class micro-class study, students can develop their spirit of cooperation and the ability to solve problems independently by conducting inquiry-based learning and working together to communicate with each other. After the teaching content is passed on to the students, the learning activities in the classroom require a higher quality activity process. The classroom through the evaluation, display, interactive discussion and other forms of student learning to check the effect; and then is the theory of Q \& A or on the machine guidance; Finally, the focus of the course to sum up. In the "flip classroom", the main task in the classroom is to allow students to have more opportunities based on the project learning application of the content, to help students complete the knowledge of the internalization of knowledge and the purpose of sublimation. Through the creation and implementation of the "student-centered" "tumbling classroom" teaching methods of information technology and digital equipment, the role of teachers is already the instructor of the classroom becoming the organizers, mentors and assistants of student learning. When the teacher becomes a mentor, most of the students will collaborate and learn together to complete the teaching efficiently.

Teaching Reflection. For students, the class is short but long, the reason why the classroom is short because the students in the flip of the presentation time is fleeting, students are often enough; the reason why the classroom is long because students focus on the traditional classroom. The time is only a dozen minutes, always a little tired, passive acceptance of knowledge indoctrination, the process is long and painful. Classroom is the classroom of students and the classroom should allow students to fully display and exchange, to achieve the purpose of internalization and sublimation. Teachers do not have to worry about teaching students in the classroom too little, as long as there is a strong classroom leadership, most students will be very natural use of extra-curricular time independent learning, students extracurricular self-learning capacity, wide range, the effect of it would be better than our teacher's imagination. Through the classroom to the students within the process of knowledge, from which to find problems, and constantly optimize the "flip classroom", while optimizing the curriculum resources. 


\section{Dual Change of the "Flip Classroom" Teaching Model for Students' Learning Way and Teachers' Teaching Way}

The implementation of "flip classroom" can not only promote the reform of classroom structure of higher education and its dual transformation of students 'learning style and teachers' teaching methods.

"Flip classroom" teaching mode has changed the traditional classroom teaching process of teacher-student relationship. Classroom is no longer teaching activities, "a word", teaching activities in the teacher is no longer an absolute "sage", and become a student "intimate friends." Teachers no longer take up a lot of classroom time to pass information and the information requires students to complete self-study after class, to achieve the process of their knowledge transfer. Classroom teaching activities are students with the learning process of doubt to participate in teachers and students, life and life interaction, cooperation, sharing and discussion. To achieve a new knowledge of the mastery and deep understanding, so that learning more active and flexible, so that students are more engaged, the learning process more interesting and vivid and efficient.

"Flip classroom" will be teaching from the "teaching - learning" model into a "learning teaching" model, is a "reverse classroom teaching mode", students become the main classroom. Help to enhance students' ability to learn independently. The use of "flip classroom" to lead the classroom structure changes, encourage students to actively explore problems, autonomy and cooperation to explore thinking, to deal with the problem.

Enhance the professional development of teachers through the teaching innovation to promote the development of teachers themselves. And strive to cultivate a number of diligent in practice to explore, good reflection of the summary, willing to sacrifice the backbone of scientific research teachers, so as to improve the overall teaching level, promote the school curriculum reform, leading the school education information process.

Internet technology is as the basis, the basic principles of Internet thinking and education as a guide to build an open, equal and shared education environment. Promote the Innovation of our teaching model. Humanized learning and individualized teaching to meet the individual needs of students help to optimize the structure of personnel training, improve the quality of teaching and the rapid development of the school far-reaching significance.

\section{Acknowledgements}

Fund Project: Research on the Teaching Model of "Tilting Classroom" Based on the Internet + Background of the "13th Five-Year Plan" of Educational Science in Jilin Province GH170984

\section{References}

[1] Song Tinglong. Research on the Strategy of Deep Integration of Information Technology and Classroom Teaching[J]. Education Modernization. 2017 (33)

[2] Zhang Yaqiu. Online learning in the context of Internet + college English flip classroom teaching mode application[J]. Heilongjiang Science. 2017 (15)

[3] Ma Yongling. Application of multimedia optimization primary school mathematics classroom teaching[J]. Science and Technology Economic Guide. 2017 (22)

[4] Meng Yan Mei. Internet + background of the English flip classroom teaching mode[J]. Higher education to explore. 2017 (S1)

[5] Xia Juan. Information technology in the language classroom teaching application[J]. Chinese character culture. 2017 (11) 